\title{
Trust Me, I'm a Doctor: Examining Changes in How Privacy Concerns Affect Patient Withholding Behavior
}

Daniel M Walker ${ }^{1}$, MPH, PhD; Tyler Johnson ${ }^{1}$, MHA; Eric W Ford ${ }^{2}$, MPH, PhD; Timothy R Huerta ${ }^{1}$, MS, PhD

${ }^{1}$ Department of Family Medicine, The Ohio State University, College of Medicine, Columbus, OH, United States

${ }^{2}$ Department of Health Policy and Management, Johns Hopkins Bloomberg School of Public Health, Baltimore, MD, United States

\section{Corresponding Author:}

Daniel M Walker, MPH, PhD

Department of Family Medicine

College of Medicine

The Ohio State University

2231 North High St

$\mathrm{Rm} 266$

Columbus, OH, 43201

United States

Phone: 16143660943

Fax: 16142932715

Email: daniel.walker@osumc.edu

\section{Abstract}

Background: As electronic health records (EHRs) become ubiquitous in the health care industry, privacy breaches are increasing and being made public. These breaches may make consumers wary of the technology, undermining its potential to improve care coordination and research.

Objective: Given the developing concerns around privacy of personal health information stored in digital format, it is important for providers to understand how views on privacy and security may be associated with patient disclosure of health information. This study aimed to understand how privacy concerns may be shifting patient behavior.

Methods: Using a pooled cross-section of data from the 2011 and 2014 cycles of the Health Information and National Trends Survey (HINTS), we tested whether privacy and security concerns, as well as quality perceptions, are associated with the likelihood of withholding personal health information from a provider. A fully interacted multivariate model was used to compare associations between the 2 years, and interaction terms were used to evaluate trends in the factors that are associated with withholding behavior.

Results: No difference was found regarding the effect of privacy and security concerns on withholding behavior between 2011 and 2014. Similarly, whereas perceived high quality of care was found to reduce the likelihood of withholding information from a provider in both 2011 (odds ratio [OR] 0.73, 95\% confidence interval [CI] 0.56-0.94) and 2014 (OR 0.61, 95\% CI 0.48-0.76), no difference was observed between years.

Conclusions: These findings suggest that consumers' beliefs about EHR privacy and security, the relationship between technology use and quality, and intentions to share information with their health care provider have not changed. These findings are counter to the ongoing discussions about the implications of security failures in other domains. Our results suggest that providers could ameliorate privacy and security by focusing on the care quality benefits EHRs provide.

(J Med Internet Res 2017;19(1):e2) doi: 10.2196/jmir.6296

\section{KEYWORDS}

privacy; electronic health records; disclosure; trust; electronic medical records; personal health information

\section{Introduction}

Electronic health records (EHRs) are now an omnipresent feature throughout the health care system, having been adopted by the majority of hospitals and physicians [1-4]. Moreover, new technologies such as health information exchange enable sharing of health records with other health care entities, and personal health records (PHRs) enable patient access to their health records [3]. As a result of this digitization, patients are more likely than ever to have their personal health information 
(PHI) - demographic information, medical history, and test and laboratory results - stored in an electronic format. In addition, a great deal of financial and other demographic data are collected and stored in a digital format for reimbursement purposes.

The growth in health information technology (HIT) use throughout the health care industry has aimed to improve care quality, as well as the efficiency of the health care system $[5,6]$. Health information technology can provide clinicians with more complete patient records at the point of care, enabling better clinical decision making, facilitating improved care coordination, and insuring patient safety as people move throughout the health care system [7]. HIT can also serve as a tool to enable better patient-provider communication, for example through secure messaging, leading to more patient-centered care $[8,9]$. Despite these potential benefits, recent high-profile, EHR security breaches reported in the media $[10,11]$ make patients wary of this shift to the digital format $[12,13]$. Patients are concerned about the privacy of their information and its security as it is stored and transferred across the health care system [14-16]. These concerns can manifest themselves in a range of behaviors that can undermine the potential of the technology to facilitate improved care. In particular, Agaku et al found that patients deliberately withheld PHI from their provider due to concerns over the security of their EHR systems [17]. However, it is possible that quality perceptions can mediate this relationship. Campos-Castillo et al found that patients reporting higher quality of care experiences had a lower likelihood of withholding PHI out of privacy and security concerns [18]. However, due to limitations of the specific iteration of the dataset used by both authors, the study by Campos-Castillo et al did not include privacy and security concern items, and the study by Agaku et al did not include quality perceptions. Thus, while these 2 studies provide a foundation for understanding how patient concerns can manifest themselves in adverse behaviors, they examined different factors that taken together might result in different PHI withholding behaviors.

The purpose of this study was to build on the aforementioned 2 studies and advance the understanding of the factors that contribute to PHI withholding behavior. Moreover, this study examined changes in the influence of privacy and security concerns on PHI withholding behavior between 2 time points. As more new technologies facilitate data sharing across the health care system, it is essential to understand the factors that lead to patient mistrust of the health care system and to observe changes in this dynamic over time. Looking at an expanded set of factors that contribute to PHI withholding behaviors can help practitioners understand the relative strength of these factors in consumers' minds. Such information can help providers and health care professionals respond to and mitigate patient privacy and security concerns in a manner that preserves the trust necessary to allow for high-fidelity PHI disclosure.

\section{Methods}

\section{Sample}

We created a pooled cross-section using data from both the 2011 and 2014 Health Information National Trends Survey (HINTS). The survey is administered as repeat cross-sections by the National Cancer Institute to a national sample of noninstitutionalized adults and gathers information regarding attitudes and perceptions about health information access and use [19]. HINTS maintains a core set of questions asked in each wave of the survey, but specific topic modules are included in separate cycles. Such is the case at-hand. The questions of interest were included only in the 2011 and 2014 surveys, restricting our research to these 2 cross-sections.

Both years of the survey were mail based. HINTS employed a stratified probability sample of the US adult, civilian, noninstitutionalized population. Addresses were randomly selected from the US Postal Service's list of residential addresses, and then an adult within a selected household was chosen to respond to the survey using the next birthday method. The next birthday method asked for the adult in the household who would next have a birthday to complete the survey and was used to eliminate bias associated with the household member most likely to receive mail. A prepaid incentive was sent at the first mailing, and multiple follow-ups were sent to recipients in order to maximize the response rate. For household with a Hispanic last name, a Spanish version of the questionnaire was delivered in addition to the English version. The total number of respondents in the 2011 and 2014 surveys were 3959 and 3677, respectively. Taking into account survey design and weighting issues, the HINTS response rates were $36.67 \%$ (3959/10796) in 2011 and $34.44 \%$ (3677/10676) in 2014. Both survey iterations yielded samples that allowed for population-level inferences after adjustment. All respondents with complete responses for all variables of interest were included in the analytic sample.

\section{Measures}

For the dependent variable, the HINTS survey asked whether the respondent had "ever kept information from (their) health care provider because (they) were concerned about the privacy and security of (their) medical record" (yes, no). This variable was used as the outcome variable for all analyses.

For our independent variables of interest, we closely followed the variable construction of related research [17,18]. Using data from the 2011 HINTS, Agaku et al evaluated the relationship between 4 indicators of privacy and security concerns and withholding behavior [17]. These 4 questions were also asked in the 2014 HINTS, making comparability possible between years. The 4 related questions about privacy and security concerns were as follows: do respondents have concerns about unauthorized access to their medical information when it is transferred electronically between providers; do respondents have concerns about unauthorized access to their medical information when it is faxed between health care providers; do they feel confident that safeguards are in place to protect their medical information from unauthorized access; and do they feel confident that they had a say in the collection, use, and sharing 
of their medical information. Respondents could answer each of these 4 questions in 3 levels: not at all concerned or confident, somewhat concerned or confident, or very concerned or confident. We tested differences in our model using all 3 levels and compared the results to using only 2 levels (not at all vs at least somewhat) and found no differences. Thus, for the purposes of simplicity, we dichotomized these variables.

Using the 2011 and 2012 HINTS surveys, Campos-Castillo et al identified a suppressor relationship between the perception that a provider had an EHR ("As far as you know, do any of your doctors or other health care providers maintain your medical information in a computerized system?") and perceived global quality of care rating on withholding behavior [18]. This suppressor relationship occurred when 1 variable, the suppressor (eg, global quality of care rating), had a positive association with a covariate of interest (eg, perception of EHR use), but a negative relationship with the outcome variable (eg, withholding behavior). Accounting for the suppressor could reveal associations between the covariate and the outcome that might not have been detectable without controlling for the suppressor. Thus, we also included the perception that a provider had an EHR (yes, no) and perceived global quality of care rating as key independent variables of interest. The HINTS asked respondents who had a nonemergency department visit in the last 12 months to rate their perception of the quality of care they received using a Likert scale (poor, fair, good, very good, excellent). For comparability to the study by Campos-Castillo et al, the quality of care variable was left as a continuous variable and coded so that higher values indicated better care.

For comparability to the study by Campos-Castillo et al, our control variables aligned with their model [18]. The control variables captured respondents' sociodemographic characteristics, health status, and health care utilization and preferences. Sociodemographic characteristics included race or ethnicity (white, black, Latino, other), gender (male, female), categorical age in years $(18-35,35-49,50-64,65-74,75$ or older), education level (less than high school, high-school, some college, college, graduate), annual category of household income (<US \$20,000, US \$20,000-\$34,999, US \$35,000-\$49,999, US $\$ 50,000-\$ 74,999$, >US $\$ 75,000)$, an indicator for living in a rural area (defined as a nonmetro county), home-ownership status (homeowner, not homeowner), marital status (married, not married), any health insurance coverage (yes, no), immigration status (born in United States, immigrant), and employment status (employed, not employed). Items about patient health status included a self-rated general health measure (poor, fair, good, very good, excellent), an anxiety and depression index (none, mild, moderate, severe), and self-care self-efficacy (not confident, a little confident, somewhat confident, very confident, completely confident). Health care utilization and preferences included the number of nonemergency room visits in the year prior to the survey (1, $2-4,5-9,10$ or more), regular health care provider (yes, no), perceived importance of personal health record access (not at all important, somewhat important, very important), and perceived importance that providers share data electronically (not at all important, somewhat important, very important).

\section{Analyses}

Weighted, but unadjusted $t$ tests or chi-squares were used to compare sample characteristics across the 2 years. Our analytic approach was designed to test the association of the independent variables of interest with withholding behavior in each year independently, as well as to test whether the relationship of the variables on withholding behavior changed between 2011 and 2014. To accomplish these tests, the 2 cross-sections were pooled together and a single fully interacted multivariate logit model, with each independent variable interacting with year, was estimated. This interacted model was solved to determine the adjusted odds ratios (OR) and confidence intervals (CI) within each year. The significance of the interaction term was used to evaluate the relative differences between years for each parameter. All results were weighted to yield US population-level inferences using a standard weighting approach developed for the HINTS dataset [20]. All analyses were conducted using Stata 14 (StataCorp LP) [21].

\section{Results}

Overall, 2217 respondents from 2011 had complete information and were included in the analytic sample, and 2176 respondents from 2014 were included. Demographic characteristics in each year are displayed in Table 1, along with the results from a chi-square test to show any differences between years.

The dependent variable of interest for this study was whether the respondent had ever withheld any PHI from a medical provider out of privacy or security concerns. No difference in the level of this behavior was observed between years: in 2011, $14.79 \%(328 / 2217)$ of respondents reported this behavior, whereas in $2014,14.93 \%$ (325/2176) of respondents reported withholding information from their provider out of privacy concerns (Table 2). Comparison of the rates of additional variables of interest between 2011 and 2014, including attitudes concerning privacy and security, quality perceptions, and health care utilization, are presented in Table 2.

To test the hypothesis that the relationship between the withholding behavior and the attitudinal variables and quality perceptions was unchanged between years, the 2 cross-sections of data were pooled and a fully interacted multivariate model predicting withholding behavior was estimated and solved for each different level of year. The interaction terms allowed for testing the relative differences of each parameter between the 2 years (see Table 3 for adjusted ORs; see Multimedia Appendix 1 for average marginal effects). This analysis revealed no changes between 2011 and 2014 in the association of privacy and security attitudes on withholding behavior. No effect of concerns regarding unauthorized access to electronic medical information on withholding behavior in either year was observed, and no difference in this effect between years was found. While concerns about unauthorized access to faxed medical information on withholding behavior was found to be significant in both 2011 and 2014, no difference in this effect was found between years. Respondent confidence that safeguards were in place to protect their medical information was not related to withholding behavior in either year, and again no difference was found between years. Lastly, there was no 
effect on respondent confidence that they had some control over their medical information on withholding behavior in either year, and no difference was found between the 2 years.

The perception of greater quality of care was found to significantly lower the odds of withholding behavior in both
2011 and 2014, but no difference was observed between years. Provider having an EHR was not found to be related to withholding behavior in either 2011 or 2014, and no difference was observed between years.

Table 1. Demographic characteristics of the analytic sample in 2011 and 2014. Frequencies and test statistics were adjusted for survey weights.

\begin{tabular}{|c|c|c|c|}
\hline Variable & $2011(\mathrm{n}=2217), \mathrm{n}(\%)$ & $2014(\mathrm{n}=2176), \mathrm{n}(\%)$ & $P$ value \\
\hline Sex & & & .30 \\
\hline Female & $1550(53.94)$ & $1407(55.48)$ & \\
\hline Male & $1024(46.06)$ & $834(44.52)$ & \\
\hline Race & & & .57 \\
\hline White & $1736(69.76)$ & $1403(71.51)$ & \\
\hline Black & $370(10.28)$ & $355(10.02)$ & \\
\hline Latino & $272(12.93)$ & $321(12.51)$ & \\
\hline Other & $176(7.02)$ & $154(5.96)$ & \\
\hline Education & & & $<.001$ \\
\hline Less than high school & $191(10.48)$ & $159(9.14)$ & \\
\hline High school & 455 (18.79) & $353(15.63)$ & \\
\hline Some college & $796(33.88)$ & $698(31.11)$ & \\
\hline College & $666(21.61)$ & $613(26.49)$ & \\
\hline Graduate & $466(15.24)$ & $418(17.62)$ & \\
\hline Age (years) & & & .59 \\
\hline $18-35$ & $408(30.70)$ & $309(29.52)$ & \\
\hline $35-49$ & $629(27.05)$ & $500(28.55)$ & \\
\hline $50-64$ & $912(26.55)$ & $810(25.62)$ & \\
\hline $65-74$ & $379(9.09)$ & $388(9.48)$ & \\
\hline $75+$ & $246(6.63)$ & $235(6.88)$ & \\
\hline Employed & $1380(58.25)$ & $1175(62.16)$ & .08 \\
\hline Income & & & $<.001$ \\
\hline$<$ US $\$ 20,000$ & $482(19.71)$ & $441(16.58)$ & \\
\hline US $\$ 20,000-\$ 34,999$ & $416(16.37)$ & $290(10.35)$ & \\
\hline US $\$ 35,000-\$ 49,999$ & $378(13.07)$ & $339(15.08)$ & \\
\hline US $\$ 50,000-\$ 74,999$ & $453(17.46)$ & 405 (18.20) & \\
\hline$>$ US $\$ 75,000$ & $845(33.40)$ & $766(39.79)$ & \\
\hline Married & $1436(53.93)$ & $1114(54.97)$ & .49 \\
\hline Rural & 409 (16.33) & $300(16.54)$ & .91 \\
\hline US Immigrant & $318(11.90)$ & $298(11.60)$ & .82 \\
\hline Homeowner & $1805(61.35)$ & $15.2(62.59)$ & .82 \\
\hline Health insurance & $2415(87.92)$ & $2039(90.80)$ & .04 \\
\hline
\end{tabular}


Table 2. Withholding behavior, privacy and security concerns, health and quality perceptions, and health care utilization compared between 2011 and 2014. Frequencies and test statistics were adjusted for survey weights.

\begin{tabular}{llll}
\hline Variable & $2011(\mathrm{n}=2217), \mathrm{n}(\%)$ & $2014(\mathrm{n}=2176), \mathrm{n}(\%)$ & $P$ value \\
\hline $\begin{array}{l}\text { Withheld information } \\
\text { Electronic information safe }\end{array}$ & $328(14.80)$ & $325(14.90)$ & .22 \\
$\quad$ & & \\
$\quad$ Not at all & $824(37.95)$ & $711(34.64)$ & 17 \\
$\quad$ At least somewhat concerned & $1472(62.05)$ & $1529(65.36)$
\end{tabular}

\section{Faxed information safe}

Not at all
At least somewhat concerned

Confident safeguards exist

Not at all confident

At least somewhat confident

Control over use of information

$$
\begin{aligned}
& \text { Not at all confident } \\
& \text { At least somewhat confident }
\end{aligned}
$$

Quality of care (mean+SE)

$$
1472 \text { (62.05) }
$$

$781(34.39)$

1538 (65.61)

$560(25.85)$

1758 (74.15)

677 (29.45)

1644 (70.55)

$4.01(0.03)$

Important that providers share electronic health record data

$\begin{array}{ll}\text { Not at all } & 128(4.94) \\ \text { Somewhat } & 704(29.25) \\ \text { Very } & 1742(65.81)\end{array}$

Important to have access to personal health record

Not at all
Somewhat

Very

Perceived provider electronic health record use

\section{General health}

$\begin{array}{ll}\text { Poor } & 79(2.39) \\ \text { Fair } & 315(11.96) \\ \text { Good } & 909(33.85) \\ \text { Very good } & 959(38.09) \\ \text { Excellent } & 312(13.71)\end{array}$

Depression

None

Mild

Moderate

Severe

Nonemergency room visits in past year

$$
\begin{aligned}
& 1 \\
& 2-4 \\
& 5-9 \\
& \geq 10
\end{aligned}
$$

Have a regular provider

Self-care efficacy, mean (SE)

$192(7.96)$
$589(21.62)$
$1793(70.42)$
$2303(88.31)$

2303 (88.31)

$$
\begin{aligned}
& 79(2.39) \\
& 315(11.96) \\
& 909(33.85) \\
& 959(38.09)
\end{aligned}
$$$$
\text { 312 (13.71) }
$$

1725 (66.84)

503 (19.67)

197 (7.15)

149 (6.34)

451 (21.54)

1398 (53.25)

460 (15.87)

265 (9.34)

2054 (73.42)

$3.87(0.03)$
.07

633 (30.47)

1601 (69.53)

.01

487 (19.72)

1747 (80.28)

623 (27.38)

1614 (72.62)

4.03 (0.04)

$102(5.83)$

615 (28.22)

1524 (65.94)

147 (5.80)

512 (22.05)

1582 (72.15)

2134 (94.54)

85 (2.10)

297 (10.16)

845 (39.12)

773 (34.57)

241 (14.05)

1584 (71.37)

404 (17.86)

$144(6.11)$

109 (4.65)

375 (19.30)

1269 (58.40)

362 (13.13)

235 (9.17)

1736 (73.24)

.93

$3.85(0.03)$

.80 
Table 3. Comparison of patient attitudes and demographic variables that are associated with withholding behavior in 2011 and 2014 based on a fully interacted model with a pooled cross-section ( $\mathrm{N}=4393$; model adjusted for survey weights).

\begin{tabular}{llll}
\hline Variable & 2011 Odds ratio (95\% CI) & 2014 Odds ratio (95\% CI) & Significance of interaction \\
\hline Electronic information safe & \multicolumn{2}{l}{ Ref } & \\
Not at all & $\operatorname{Ref}^{\mathrm{a}}$ & $1.82(0.78-4.22)$ & .85 \\
At least somewhat concerned & $1.63(0.74-3.62)$ &
\end{tabular}

\section{Faxed information safe}

Not at all Ref Ref

At least somewhat concerned

$7.09(2.56-19.66)^{\mathrm{b}}$

\section{Confident information safe}

Not at all confident Ref Ref

At least somewhat confident

$0.73(0.34-1.57)$

$1.54(0.66-3.60)$

\section{Control information}

Not at all confident
At least somewhat confident

Quality of care
Ref

$1.71(0.91-3.21)$

$0.72(0.56-0.94)^{\mathrm{c}}$
Ref

$\begin{array}{ll}1.10(0.55-2.20) & .35 \\ 0.61(0.48-0.76)^{\mathrm{b}} & .30\end{array}$

Ref

$0.56(0.10-3.02)$

$0.72(0.14-3.61)$

Ref

$1.31(0.26-6.52) \quad .17$

$1.81(0.45-7.30) \quad .16$

$0.70(0.30-1.66) \quad .17$

Ref

$1.10(0.67-1.80) \quad .40$

Ref

$0.98(0.43-2.24) \quad .37$

$1.37(0.53-3.57) \quad .84$

$1.97(0.81-4.81) \quad .82$

Ref

$\begin{array}{ll}1.16(0.40-3.36) & .35 \\ 0.90(0.37-2.19) & .73 \\ 0.86(0.33-2.24) & .92 \\ 1.43(0.57-3.63) & .79\end{array}$

Ref

$1.03(0.49-2.20) \quad .39$

$0.63(0.31-1.30) \quad .27$ 


\begin{tabular}{|c|c|c|c|}
\hline Variable & 2011 Odds ratio $(95 \% \mathrm{CI})$ & 2014 Odds ratio $(95 \% \mathrm{CI})$ & Significance of interaction \\
\hline $65-74$ & $0.87(0.38-1.98)$ & $0.59(0.24-1.48)$ & .54 \\
\hline $75+$ & $0.67(0.18-2.50)$ & $0.26(0.07-0.94)^{\mathrm{c}}$ & .32 \\
\hline Employed & $1.79(0.96-3.35)$ & $1.53(0.83-2.84)$ & .83 \\
\hline \multicolumn{4}{|l|}{ Income } \\
\hline$<$ US $\$ 20,000$ & Ref & Ref & \\
\hline US $\$ 20,000-\$ 34,999$ & $0.76(0.30-1.93)$ & $0.97(0.43-2.21)$ & .70 \\
\hline US $\$ 35,000-\$ 49,999$ & $0.57(0.23-1.42)$ & $0.99(0.39-2.54)$ & .40 \\
\hline US $\$ 50,000-\$ 74,999$ & $0.77(0.35-1.69)$ & $0.84(0.38-1.85)$ & .87 \\
\hline$>$ US $\$ 75,000$ & $0.55(0.24-1.25)$ & $0.68(0.29-1.60)$ & .72 \\
\hline Married & $0.79(0.50-1.24)$ & $0.72(0.41-1.26)$ & .85 \\
\hline Rural & $1.00(0.54-1.86)$ & $1.18(0.47-2.92)$ & .77 \\
\hline US immigrant & $1.01(0.55-1.88)$ & $0.73(0.37-1.41)$ & .46 \\
\hline Homeowner & $1.21(0.67-2.21)$ & $0.71(0.41-1.23)$ & .19 \\
\hline Health insurance & $1.35(0.47-3.88)$ & $0.95(0.41-2.21)$ & .61 \\
\hline \multicolumn{4}{|l|}{ General health } \\
\hline Poor & Ref & Ref & \\
\hline Fair & $1.26(0.27-5.92)$ & $0.41(0.12-1.39)$ & .25 \\
\hline Good & $1.50(0.33-6.72)$ & $0.28(0.08-1.03)$ & .10 \\
\hline Very good & $2.13(0.46-9.77)$ & $0.41(0.11-1.50)$ & .11 \\
\hline Excellent & $2.16(0.44-10.67)$ & $0.49(0.10-2.31)$ & .19 \\
\hline \multicolumn{4}{|l|}{ Depression } \\
\hline None & Ref & Ref & \\
\hline Mild & $1.14(0.61-2.13)$ & $0.87(0.42-1.81)$ & .57 \\
\hline Moderate & $2.71(1.14-6.42)^{\mathrm{c}}$ & $1.85(0.59-5.79)$ & .59 \\
\hline Severe & $1.13(0.39-3.26)$ & $1.13(0.42-3.01)$ & .99 \\
\hline \multicolumn{4}{|c|}{ Nonemergency room visits in past year } \\
\hline 1 & Ref & Ref & \\
\hline $2-4$ & $0.91(0.52-1.60)$ & $1.06(0.49-2.29)$ & .75 \\
\hline $5-9$ & $1.08(0.50-2.32)$ & $1.02(0.39-2.65)$ & .92 \\
\hline$\geq 10$ & $1.10(0.45-2.73)$ & $1.66(0.66-4.18)$ & .53 \\
\hline Have a regular provider & $0.98(0.56-1.72)$ & $1.75(0.95-3.23)$ & .17 \\
\hline Mean self-care efficacy & $0.97(0.69-1.38)$ & $0.97(0.65-1.44)$ & .97 \\
\hline
\end{tabular}

${ }^{\mathrm{a}}$ Ref: reference category.

${ }^{\mathrm{b}} P<.001$.

${ }^{\mathrm{c}} P<.05$.

\section{Discussion}

\section{Principal Findings}

Public perception of the safety of their medical records is critical to not only encouraging full disclosure to their health care provider, but also supporting adoption and use of electronic modes of health communication made available by new technologies. Distrust can lead to withholding of information from providers and undermine the delivery of high-quality,

efficient care. The aim of our analysis was to determine the factors that contribute to this withholding behavior, and how the effect of these factors may be shifting over time. In short, we found that the association between patient concerns and withholding information from a provider remained unchanged between 2011 and 2014 .

Earlier work using 2011 HINTS data found that respondents with concerns about both faxed and electronic data, and lack of confidence that safeguards were in place to protect medical 
information, were more likely to withhold information from their provider [17]. Our model included a more extensive set of control variables, as well as indicators of quality and provider EHR use, and found no such relationships to exist in either 2011 or 2014. This discordance between the 2 analyses suggests that patient concerns over the safety of their medical information may not be adversely related to their disclosure of PHI to their providers. Alternatively, other factors beyond general privacy and security concerns may lead to withholding behaviors, such as lack of trust, stigma, or concerns about insurance rates [22-24].

In contrast to the lack of replicability of the earlier findings regarding the relationship between security and privacy concerns, and withholding behavior, our analysis did observe findings similar to those of Campos-Castillo et al regarding the association between quality and withholding behavior [18]. The original work did not include the privacy and security questions used in this analysis, but did include an identical set of covariates. Nonetheless, Campos-Castillo et al found that perceptions of greater quality of care reduced the odds of PHI withholding behavior [18]. This relationship was observed in our study in both 2011 and 2014, effectively reinforcing the earlier work of Campos-Castillo et al [18]. Interestingly, no difference was observed in the correlation between quality and withholding behavior between years. This latter finding suggests that despite the rise in ubiquity of EHRs alongside more public privacy breaches, high perceived quality of care may still trump any concerns that contribute to withholding behavior.

Related to this issue, our study did observe an increase in perceived EHR use between 2011 and 2014. Despite similar findings regarding quality perceptions between our study and the study by Campos-Castillo et al, our work found no relationship between perceived provider EHR use and withholding behavior, while their study did find the presence of such relationship [18]. To be specific, the study by Campos-Castillo et al found that quality acted as a suppressor variable that moderated the relationship between perceived EHR use and patient withholding behavior [18]. The variables regarding attitudes about EHR and privacy and security may be acting as confounders in the relationship, which would explain the significance in the earlier study but not this one.

Overall, our analysis suggests that in spite of the existence of security and privacy concerns, focusing resources on the delivery of high-quality care may be an effective strategy to foster patient trust. Patients may perceive quality as an indicator of a provider's carefulness with their medical information. Quality may also help to build the patient-provider relationship [25,26]. Alternatively, the notion of privacy is evolving as more and more personal information is held on the Internet [27,28]. It may be possible that given the increasing digitization of personal information, the US population is willing to accept greater amounts of privacy risks of their personal data as a trade-off for greater convenience or better quality of care. This is a ripe area for future research, as the field of health services research should consider the role that changes in collective ideas of privacy may be playing in how patients relate to the health care system.

\section{Limitations}

Our analysis faced 3 important limitations. First, the administration of HINTS combined with the weighting technique allowed for the survey to be nationally representative. However, selection bias might have remained that limited the generalizability of the sample. Furthermore, our dependent variable (withholding behavior) could be related to survey response, and respondents with complete answers to all questions might systematically differ from nonrespondents. Related to this issue, because the HINTS survey was administered to only noninstitutionalized individuals, the findings regarding withholding behavior might be biased toward the outpatient environment. Continued monitoring of the factors that contribute to patient withholding with future iterations of HINTS can help to assess the impact of this bias and evaluate the true relationship between the variables of interest and the outcome.

Second, all information in HINTS was self-reported, potentially resulting in unreliable responses. This concern was particularly relevant to the withholding behavior question that was subject to social desirability bias [29]. Third, while our analysis did compare data from 2 different years, the cross-sectional nature of HINTS made the determination of causal inference challenging. Specifically, HINTS asked whether a person had ever withheld information from their provider, leaving open the possibility that withholding behavior preceded concerns about privacy and security, or quality perceptions. This issue was further complicated by the ordering of the questions in both cycles of the HINTS survey used in this study, where the question about perception of quality of care preceded the questions about perceived EHR use and withholding behavior. Furthermore, the frame of reference for the quality of care question was “...in the past 12 months," while for EHR use or withholding behavior question, the frame of reference was undefined or "ever." As a result, the responses to these questions might have drawn on different experiences, and might not necessarily reference the same encounter with the health care system. Thus, our findings regarding quality of care might be biased away from the null, and our study results should be interpreted with these measurement limitations in mind. However, despite the inability to detect causality, the national representativeness of HINTS makes it useful to identify macro trends at the individual variable level. Future studies that examine the effect of privacy and security concerns on patient withholding behavior may take a more micro approach, potentially using in-depth interviews to better understand how these concerns may manifest themselves and to identify specific omitted factors.

\section{Conclusions}

Monitoring and assessing how technological advances may be related to patient behavior is critical to insure high-quality care and patient safety. In contrast to previous findings, the analysis presented in this study suggested minimal effects of privacy and security concerns on PHI withholding behavior, and that this relationship was constant over time. Similarly, the relationship between quality perceptions and withholding behavior was also constant over time, yet negatively correlated 
at both time points. Thus, our findings suggested that improving quality can buffer privacy and security concerns. While technological safeguards to protect patient health information remains important, health professionals should not forget that individual relationships remain the foundation of the patient's experience with the health care system.

\section{Authors' Contributions}

TJ and DW conducted the data analysis. DW drafted and edited the manuscript. DW, EW, and TH conceived of and oversaw all stages of this study. All authors approved the final manuscript.

\section{Conflicts of Interest}

None declared.

\section{Multimedia Appendix 1}

Average marginal effects of patient attitudes and demographic variables that are associated with withholding behavior, in 2011 and 2014, based on a fully interacted model with a pooled cross-section $(n=4393)$.

[PDF File (Adobe PDF File), 54KB-Multimedia Appendix 1]

\section{References}

1. Adler-Milstein J, DesRoches CM, Furukawa MF, Worzala C, Charles D, Kralovec P, et al. More than half of US hospitals have at least a basic EHR, but stage 2 criteria remain challenging for most. Health Aff (Millwood) 2014 Sep;33(9):1664-1671. [doi: $10.1377 /$ hlthaff.2014.0453] [Medline: 25104826]

2. DesRoches CM, Charles D, Furukawa MF, Joshi MS, Kralovec P, Mostashari F, et al. Adoption of electronic health records grows rapidly, but fewer than half of US hospitals had at least a basic system in 2012. Health Aff (Millwood) 2013 Aug;32(8):1478-1485. [doi: 10.1377/hlthaff.2013.0308] [Medline: 23840052]

3. Furukawa MF, Patel V, Charles D, Swain M, Mostashari F. Hospital electronic health information exchange grew substantially in 2008-12. Health Aff (Millwood) 2013 Aug;32(8):1346-1354. [doi: 10.1377/hlthaff.2013.0010] [Medline: 23918477]

4. Mennemeyer ST, Menachemi N, Rahurkar S, Ford EW. Impact of the HITECH Act on physicians' adoption of electronic health records. J Am Med Inform Assoc 2016 Mar;23(2):375-379. [doi: 10.1093/jamia/ocv103] [Medline: 26228764]

5. Buntin MB, Burke MF, Hoaglin MC, Blumenthal D. The benefits of health information technology: a review of the recent literature shows predominantly positive results. Health Aff (Millwood) 2011 Mar;30(3):464-471 [FREE Full text] [doi: 10.1377/hlthaff.2011.0178] [Medline: 21383365]

6. Shekelle PG, Morton SC, Keeler EB. Costs and benefits of health information technology. Evid Rep Technol Assess (Full Rep) 2006 Apr(132):1-71. [Medline: 17627328]

7. Kaelber DC, Bates DW. Health information exchange and patient safety. J Biomed Inform 2007 Dec;40(6 Suppl):S40-S45 [FREE Full text] [doi: 10.1016/j.jbi.2007.08.011] [Medline: 17950041]

8. Asan O, Carayon P, Beasley JW, Montague E. Work system factors influencing physicians' screen sharing behaviors in primary care encounters. Int J Med Inform 2015 Oct;84(10):791-798. [doi: 10.1016/j.ijmedinf.2015.05.006] [Medline: 26049312]

9. Archer N, Fevrier-Thomas U, Lokker C, McKibbon KA, Straus SE. Personal health records: a scoping review. J Am Med Inform Assoc 2011;18(4):515-522 [FREE Full text] [doi: 10.1136/amiajnl-2011-000105] [Medline: 21672914]

10. Abelson R, Creswell J. Data breach at Anthem may forecast a trend. New York Times. 2015 Feb 06. URL: http://www. nytimes.com/2015/02/07/business/data-breach-at-anthem-may-lead-to-others.html? r=0 [accessed 2016-12-20] [WebCite Cache ID 6mtmT4vPF]

11. Wadell K. Hospitals aren't the only ones bleeding stolen health records. The Atlantic. 2015 Dec 16. URL: http://www. theatlantic.com/technology/archive/2015/12/hospitals-arent-the-only-ones-bleeding-stolen-health-records/420636/ [accessed 2016-12-20] [WebCite Cache ID 6mtm8cPAp]

12. Ancker JS, Silver M, Miller MC, Kaushal R. Consumer experience with and attitudes toward health information technology: a nationwide survey. J Am Med Inform Assoc 2013 Jan 1;20(1):152-156 [FREE Full text] [doi: 10.1136/amiajnl-2012-001062] [Medline: 22847306$]$

13. Kwon J, Johnson ME. The Market Effect of Healthcare Security: Do Patients Care about Data Breaches? 2015 Presented at: 14th Annual Workshop on the Economics of Information Security (WEIS 15); June, 22-23; The Netherlands.

14. Ancker JS, Brenner S, Richardson JE, Silver M, Kaushal R. Trends in public perceptions of electronic health records during early years of meaningful use. Am J Manag Care 2015 Aug;21(8):e487-e493. [Medline: 26625503]

15. Patel V, Hughes P, Savage L, Barker W. Individuals' perceptions of the privacy and security of medical records. Healthit. 2015 Jun. URL: https://www.healthit.gov/sites/default/files/briefs/oncdatabrief27june2015privacyandsecurity.pdf [accessed 2016-12-21] [WebCite Cache ID 6muvUHEZb] 
16. Patel V, Beckjord E, Moser RP, Hughes P, Hesse BW. The role of health care experience and consumer information efficacy in shaping privacy and security perceptions of medical records: national consumer survey results. JMIR Med Inform 2015;3(2):e14 [FREE Full text] [doi: 10.2196/medinform.3238] [Medline: 25843686]

17. Agaku IT, Adisa AO, Ayo-Yusuf OA, Connolly GN. Concern about security and privacy, and perceived control over collection and use of health information are related to withholding of health information from healthcare providers. $\mathrm{J}$ Am Med Inform Assoc 2014;21(2):374-378 [FREE Full text] [doi: 10.1136/amiajnl-2013-002079] [Medline: 23975624]

18. Campos-Castillo C, Anthony DL. The double-edged sword of electronic health records: implications for patient disclosure. J Am Med Inform Assoc 2015 Apr;22(e1):e130-e140 [FREE Full text] [doi: 10.1136/amiajnl-2014-002804] [Medline: 25059953]

19. Finney Rutten LJ, Davis T, Beckjord EB, Blake K, Moser RP, Hesse BW. Picking up the pace: changes in method and frame for the health information national trends survey (2011-2014). J Health Commun 2012;17(8):979-989 [FREE Full text] [doi: 10.1080/10810730.2012.700998] [Medline: 23020763]

20. Moser R, Naveed S, Cantor D, Blake K, Rutten L, Ramirez A. Integrative analytic methods using population-level cross-sectional data. Hints.cancer. 2013. URL: https://hints.cancer.gov/docs/HINTS IDA Report.pdf [accessed 2016-12-21] [WebCite Cache ID 6muvnx2BR]

21. StataCorp. Stata statistical software: Release 14. College Station, TX: StataCorp LP; 2015.

22. Hall MA, Zheng B, Dugan E, Camacho F, Kidd KE, Mishra A, et al. Measuring patients' trust in their primary care providers. Med Care Res Rev 2002 Sep;59(3):293-318. [Medline: 12205830]

23. Stewart DE, Cheung AM, Duff S, Wong F, McQuestion M, Cheng T, et al. Long-term breast cancer survivors: confidentiality, disclosure, effects on work and insurance. Psychooncology 2001;10(3):259-263. [Medline: 11351378]

24. Dew K, Morgan S, Dowell A, McLeod D, Bushnell J, Collings S. 'It puts things out of your control': fear of consequences as a barrier to patient disclosure of mental health issues to general practitioners. Sociol Health Illn 2007 Nov;29(7):1059-1074 [FREE Full text] [doi: 10.1111/j.1467-9566.2007.01022.x] [Medline: 18092983]

25. Hall JA, Roter DL, Rand CS. Communication of affect between patient and physician. J Health Soc Behav 1981 Mar;22(1):18-30. [Medline: 7240703]

26. Lang F, Floyd MR, Beine KL, Buck P. Sequenced questioning to elicit the patient's perspective on illness: effects on information disclosure, patient satisfaction, and time expenditure. Fam Med 2002 May;34(5):325-330. [Medline: 12038713]

27. Blobel B. Paradigm Changes of Health Systems Towards Ubiquitous, Personalized Health Lead to Paradigm Changes of the Security and Privacy Ecosystems. Int J Biomedicine and Healthcare 2015;3(1):6-11.

28. Dinev T, Albano V, Xu H, D'Atri A, Hart P. Individuals' Attitudes Towards Electronic Health Records: A Privacy Calculus Perspective. In: Gupta A, Patel V, Greenes R, editors. Advances in Healthcare Informatics and Analytics. Switzerland: Springer International Publishing; 2016:19-50.

29. Richman W, Kiesler S, Weisband S, Drasgow F. A meta-analytic study of social desirability distortion in computer-administered questionnaires, traditional questionnaires, and interviews. J Appl Psychol 1999;84(5):754-775. [doi: $\underline{10.1037 / 0021-9010.84 .5 .754]}$

\author{
Abbreviations \\ EHR: electronic health record \\ HINTS: Health Information and National Trends Survey \\ HIT: health information technology \\ PHI: personal health information \\ PHR: personal health record
}

Edited by G Eysenbach; submitted 30.06.16; peer-reviewed by S Rahurkar, B Hesse, A Kazley; comments to author 04.08.16; revised
version received 21.09.16; accepted 30.11.16; published 04.01.17
Please cite as:
Walker DM, Johnson T, Ford EW, Huerta TR
Trust Me, I'm a Doctor: Examining Changes in How Privacy Concerns Affect Patient Withholding Behavior
J Med Internet Res 2017;19(1):e2
URL: $\underline{\text { http://www.jmir.org/2017/1/e2/ }}$
doi: $\underline{10.2196 / j m i r .6296}$
PMID: $\underline{28052843}$

CDaniel M Walker, Tyler Johnson, Eric W Ford, Timothy R Huerta. Originally published in the Journal of Medical Internet Research (http://www.jmir.org), 04.01.2017. This is an open-access article distributed under the terms of the Creative Commons 
Attribution License (http://creativecommons.org/licenses/by/2.0/), which permits unrestricted use, distribution, and reproduction in any medium, provided the original work, first published in the Journal of Medical Internet Research, is properly cited. The complete bibliographic information, a link to the original publication on http://www.jmir.org/, as well as this copyright and license information must be included. 